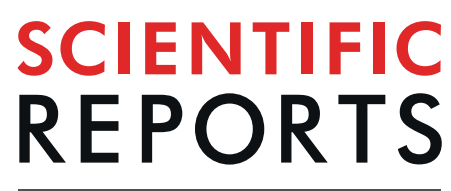

natureresearch

\title{
OPEN Antimicrobial properties of the novel bacterial isolate Paenibacilllus sp. SMB1 from a halo-alkaline lake in India
}

Received: 12 October 2018

Accepted: 17 July 2019

Published online: 09 August 2019

\author{
Harjodh Singh ${ }^{1,2,4}$, Manpreet Kaur ${ }^{1,2,4}$, Manoj Jangra ${ }^{3}$, Sunita Mishra ${ }^{1,2}$, Hemraj Nandanwar ${ }^{1,3}$ \\ \& Anil Kumar Pinnaka ${ }^{1,4}$
}

Antibiotic-resistance is ever growing burden on our society for the past many years. Many synthetic chemistry approaches and rational drug-design have been unable to pace up and tackle this problem. Natural resources, more specifically, the microbial diversity, on the other hand, make a traditional and still the best platform to search for new chemical scaffolds and compounds. Here, we report the antimicrobial characteristics of novel bacterial isolate from a salt lake in India. We screened the bacterial isolates for their inhibitory activity against indicator bacteria and found that four novel species were able to prevent the growth of test strains studied in vitro. Further, we characterized one novel species $\left(S M B 1^{\top}=S L 4-2\right)$ using polyphasic taxonomic approaches and also purified the active ingredient from this bacterium. We successfully characterized the antimicrobial compound using mass spectroscopy and amino acid analysis. We also allocated two novel biosynthetic gene clusters for putative bacteriocins and one novel non-ribosomal peptide gene cluster in its whole genome. We concluded that the strain SMB1 ${ }^{\top}$ belonged to the genus Paenibacillus with the pairwise sequence similarity of $98.67 \%$ with Paenibacillus tarimensis DSM $19409^{\top}$ and we proposed the name Paenibacillus sambharensis sp. nov. The type strain is SMB1 ${ }^{\top}\left(=\right.$ MTCC $12884=$ KCTC $\left.33895^{\top}\right)$.

Increasing burden of antibiotic resistance around the globe is of grave concern. The present antibiotics are almost ineffective to fight against the deadly infections caused by many bacteria ${ }^{1}$. It is estimated that till 2050, around 10 million people may die from antimicrobial-resistant infections if current scenario persists. Presently, the methods and measures taken globally to tackle this problem are insufficient and slow ${ }^{2}$. Various strategies such as high throughput screening of synthetic chemical compound libraries and determination of new targets with the help of genomic studies were not successful in finding potential antimicrobial entities ${ }^{3}$.

In recent years, natural products have gained significant attention to overcome the gap in drug discovery and development due to their structure versatility and potential biological activity ${ }^{4-8}$. Majority of the antibiotics consumed at present are either the natural compounds or derivatives thereof, which were discovered from soil Actinomycetes in 1940-1960s i.e. golden era of antibiotics. The soil has been extensively mined since then for the new antimicrobial molecules and now seems exhausted. Therefore, looking for alternative microbial sources or unique niches of microbes would be an asset to find novel antimicrobial compounds.

Biodiversity of halophilic bacteria holds a huge potential to produce new and unexplored antimicrobial entities. Tonima Kamat et al. reported the antimicrobial activities demonstrated by the halophilic bacteria isolated from salt pans ${ }^{9}$. Similarly, Toktham et al. also reported the effectiveness of the halophiles as antimicrobials ${ }^{10,11}$. Recently, Atirah et al. discussed the purification of a bacteriocin from Halomonas sp. ${ }^{12}$. Intracellular proteins of Virgibacillus marismortui and Terribacillus halophilus, i.e., glucanase and chinatase respectively have been reported for their antimicrobial activity ${ }^{13}$. Based on these observations and since there are not many reports

${ }^{1}$ Academy of Scientific and Innovative Research, (AcSIR), CSIR Campus, Chennai, India. ${ }^{2}$ Council of Scientific and Industrial Research (CSIR) - Central Scientific Instruments Organisation, Sector 30C, Chandigarh, 160030, India. ${ }^{3}$ Clinical Microbiology \& Bioactive Screening Laboratory, Council of Scientific \& Industrial Research -Institute of Microbial Technology, Sector -39A, Chandigarh, India. ${ }^{4} \mathrm{MTCC}-M i c r o b i a l$ Type Culture Collection \& Gene Bank, CSIRInstitute of Microbial Technology, Chandigarh, 160036, India. Harjodh Singh and Manpreet Kaur contributed equally. Correspondence and requests for materials should be addressed to A.K.P. (email: apinnaka@imtech.res.in) 


\begin{tabular}{|c|c|c|c|c|c|c|c|c|}
\hline \multirow[b]{2}{*}{ S.No } & \multirow[b]{2}{*}{ Strain } & \multirow[b]{2}{*}{ Closest homolog } & \multicolumn{2}{|c|}{$24 \mathrm{~h}$ Supernatant } & \multicolumn{2}{|c|}{$48 \mathrm{~h}$ Supernatant } & \multicolumn{2}{|l|}{$48 \mathrm{~h}$ Extract } \\
\hline & & & ATCC-25923 & ATCC-6633 & ATCC-25923 & ATCC-6633 & ATCC-25923 & ATCC-6633 \\
\hline 1 & A 17 & Halomonas salifodinea & - & - & - & - & + & - \\
\hline 2 & A9 & Halomonas mongoliensis & - & - & - & - & - & + \\
\hline 3 & $8 \mathrm{~b}$ & Pseudomonas stutzeri & - & - & - & - & + & - \\
\hline 4 & SL $12-4$ & Bacillus licheniformis & + & - & + & - & + & - \\
\hline 5 & $8 \mathrm{a}$ & Paracoccus aestuarii & - & - & - & - & + & - \\
\hline 6 & SMB1 $^{\mathrm{T}}$ & Paenibacillus tarimensis & - & - & - & - & + & + \\
\hline 7 & $7 \mathrm{a}$ & Halomonas salfodinea & - & - & - & - & + & - \\
\hline 8 & SL 6-1 & Halomonas salifodinae & - & - & + & - & + & - \\
\hline 9 & SMB-4 ${ }^{\mathrm{T}}$ & Salibacterium nitratireducens* & - & - & + & + & - & - \\
\hline 10 & AK74 ${ }^{\mathrm{T}}$ & Bacillus lacus* & - & + & - & + & + & + \\
\hline 11 & $\mathbf{A K 7 3}^{\mathrm{T}}$ & Bacillus alkalilacus* & - & - & - & - & + & + \\
\hline 12 & SL4-1R & Alkalibacterium pelagium & - & - & - & - & - & + \\
\hline 13 & SL6-1R & Halomonas salifodinae & - & - & - & - & + & + \\
\hline 14 & SL5-1R & Bacillus sonorensis & - & - & - & - & + & + \\
\hline 15 & SL6-3R & Halomonas salifodinae & - & - & - & - & + & - \\
\hline
\end{tabular}

Table 1. Screening results for the production of antimicrobial compounds. ATCC-25923-Staphylococcus aureus; ATCC-6633 - Bacillus subtilis. *These strains are already described as novel species by our group previously. ${ }^{+}$no growth of indicator strain around the well; ${ }^{-}$growth of indictor strain around well.

available from India showing the antimicrobial potential of halophiles, we studied the biodiversity of halophilic bacteria isolated from Sambhar Lake in Rajasthan, India. In the present study, we screened the bacterial isolates from this lake for their antimicrobial activity. We have characterized one novel species strain SMB1 in this manuscript. Moreover, we purified and characterized the antimicrobial compound from the fermentation broth. Tandem mass spectroscopy, amino acid analysis, and whole genome data were used to identify this antimicrobial compound. Additionally, we predicted two novel bacteriocin gene clusters and one non-ribosomal peptide gene cluster in the whole genome of this novel species. The novel species $\mathrm{SMB}^{\mathrm{T}}$ was characterized using polyphasic taxonomic approaches.

\section{Results}

Antimicrobial screening of bacterial strains. More than hundred bacterial strains were isolated from the Sambar Lake and screened for their antimicrobial activity against E. coli (MTCC 1610), Staphylococcus aureus (ATCC 25923), Bacillus subtilis (ATCC 6633), and Candida albicans (MTCC 224). The cell-free supernatant and/ or crude fermentation extract of fifteen isolates inhibited the growth of Gram-positive bacteria. These positive isolates were identified based on their $16 \mathrm{~S}$ rRNA gene sequences. They comprised of four novel species among them as shown in Table 1. Our group recently described three of these novel species viz; SMB4 ${ }^{\mathrm{T} 14}, \mathrm{AK} 73^{\mathrm{T} 15}$ and $\mathrm{AK} 74^{\mathrm{T} 16}$. In the current work, we characterized $\mathrm{SMB} 1^{\mathrm{T}}$ as novel species and studied its antimicrobial activity.

Identification and characterization of the antimicrobial compound from strain $\mathrm{SMB1}^{\top}$. The strain $\mathrm{SMB}^{\mathrm{T}}$ showed consistent antagonistic activity against Gram-positive bacteria. Partial purification of the antimicrobial compound was achieved through cation-exchange chromatography. The active fraction was eluted at $0.5 \mathrm{M} \mathrm{NaCl}$ concentration. Further, the purification of the active compound was performed on RP-HPLC. Figure 1A shows the HPLC chromatogram of cation-active dialysate. The active compound eluted at $\mathrm{RT}=32.7 \mathrm{~min}$. The purity of the compound was more than $95 \%$ (Fig. $1 \mathrm{~B}$ ). The pure compound showed $\mathrm{m} / \mathrm{z}$ value at $1422.76[\mathrm{M}+\mathrm{H}]^{+}$in LC-ESI-MS and one doubly charged ion at $711.88[\mathrm{M}+2 \mathrm{H}]^{+2}$ was also formed as illustrated in Fig. 2A. The molecular mass of the compound was deduced as 1421.75 Da. Tandem MS and amino acid analysis were further carried out to identify the compound. In the amino acid analysis, we found the presence of aspartic acid, glutamic acid, histidine, isoleucine, leucine, phenylalanine, lysine and one non-standard amino acid which later was identified as ornithine Fig. 2B. MS-MS data also supported the amino acid composition. Mass spectroscopy and amino acid profile revealed that the active compound belongs to bacitracin family and its molecular mass was similar to that of bacitracin $\mathrm{A}\left(\mathrm{C}_{66} \mathrm{H}_{103} \mathrm{~N}_{17} \mathrm{O}_{16} \mathrm{~S}\right.$, calc. mass $\left.1421.749 \mathrm{Da}\right)$. The MS/MS data was consistent with what we observed for standard bacitracin A (Alfa Aeser, Thermofisher Scientific, India) (Fig. S1). We studied the MS/MS data extensively and annotated all the $b$ and $y$ ions present in the raw spectrum (Fig. 3A). Bacitracin A is a cyclic peptide containing twelve amino acid residues ${ }^{17,18}$. The lysine at position 6 is involved in double linkage with ornithine at position 7 using $\alpha$-carbonyl group while with asparagine at position 12 using $\varepsilon$-amino group. In tandem mass spectroscopy, such residues are most vulnerable and thus we observed two series of $b$ and $y$ ions upon linearization of the peptide after the breakage of either of the bonds. Each bond leads to a different primary sequence and we were able to assign both series of ions as can be seen in Fig. 3B. For further confirmation, we performed the comparative analysis of the antimicrobial compound produced by the $\mathrm{SMB}^{\mathrm{T}}$ strain with standard bacitracin A. As shown in Fig. 4A,B, both compounds had significantly similar retention time in analytical RP-HPLC. Moreover, the antimicrobial activity spectrum against selected indicator strains was also similar (Fig. S2). This data collectively suggested that compound isolated in this study is bacitracin A. 

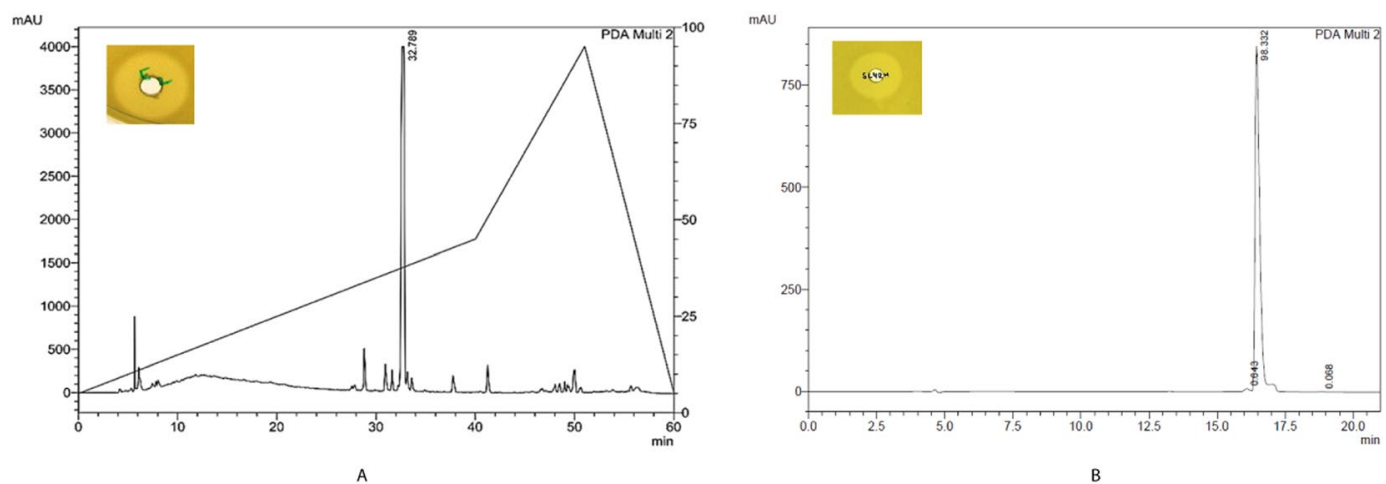

Figure 1. (A) Profile of the cation exchange active peak of the antimicrobial compound of SMB1 ${ }^{\mathrm{T}}$. The activity of the peak is inserted in the picture; (B) HPLC profile of the purified compound of SMB1 ${ }^{\mathrm{T}}$. The activity of the peak is inserted in the picture.

A

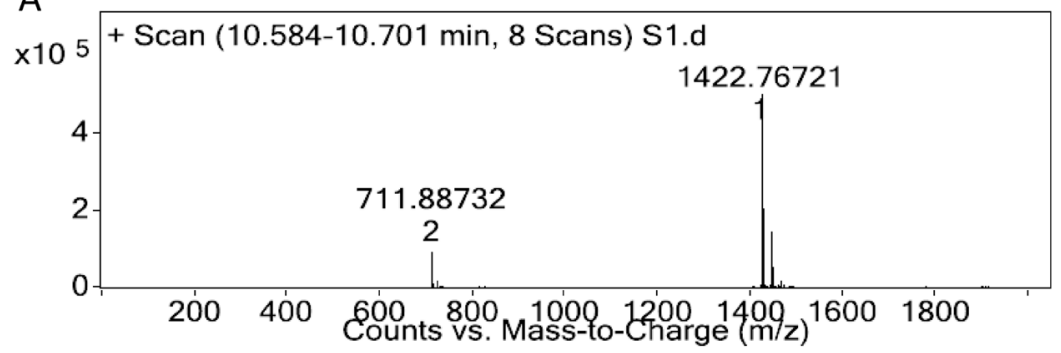

B

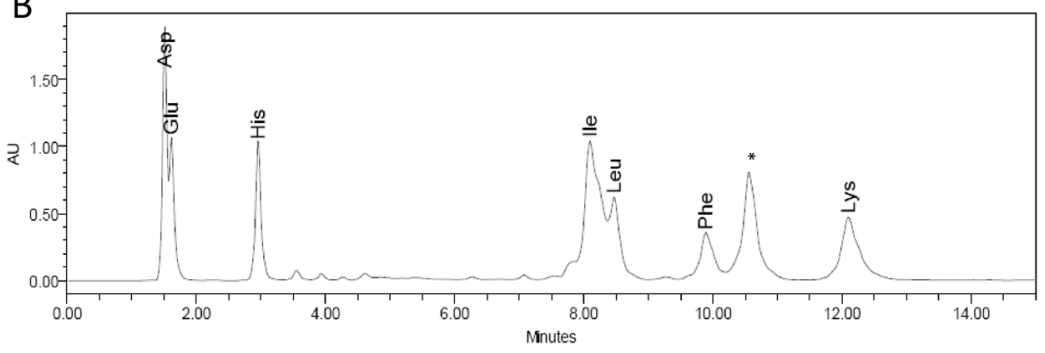

Figure 2. (A) LCMS profile of active fraction of antimicrobial compound of $\mathrm{SMB}^{\mathrm{T}}$; (B) Amino Acid chromatogram of the pure antimicrobial compound of $\mathrm{SMB} 1^{\mathrm{T}}$.

Whole genome analysis and putative biosynthetic gene clusters. The size of the genome of the strain $\mathrm{SMB1}^{\mathrm{T}}$ is 5661449 bp with 4943914 total reads (N50 size 247161, L50 8 and N75 176162). This sequence was the draft genome of the strain $S M B 1^{\mathrm{T}}$ in which 63 contigs were obtained. We predicted genes from the ABySS assembled contigs using Glimmer ${ }^{19}$. We found 5,282 genes in the assembly. The $\mathrm{G}+\mathrm{C}$ content as predicted in the genome analysis was $53.0 \%$, this falls in the $\mathrm{G}+\mathrm{C}$ content range i.e $45-54 \%$ generally found in the genus Paenibacillus $^{20}$. The assembled fasta file was uploaded on Rapid Annotation using Subsystem Technology (RAST) tool. This is a fully automated system for genome annotations. For further confirmation of the production of bacitracin by the strain $S M B 1^{\mathrm{T}}$, we looked for the genes encoding for the synthesis of the bacitracin, we were able to locate the partial cluster at contig 383 showing the presence of Bacitracin synthetase 3 (BA3) gene as shown in Fig. S3. This enzyme complex encodes for the amino acids that are required for the synthesis of bacitracin. Hence, with this annotation results we confirmed that our strain $S M B 1^{\mathrm{T}}$ is having the genes for the synthesis of bacitracin which was purified in the present study. Moreover, we subjected the whole genome sequence to other tools like as anti-SMASH (Antibiotics \& Secondary Metabolites Analysis Shell) and BAGEL to find out the genes associated with the antimicrobials and the secondary metabolites. Two novel biosynthetic gene clusters were obtained in the BAGEL analysis (Fig. 5A,B). The gene clusters encoding for the lasso-peptide (cluster1) and thiopeptide (cluster2), the putative bacteriocins were identified using BAGEL 3. Another novel biosynthetic gene cluster was identified using anti-SMASH; it belonged to non-ribosomal peptide (NRP) secondary metabolite, and was located on contig 41 as shown in Fig. 5C. The software predicted thirteen adenylation domains and six epimerase domains. This analysis suggests that the predicted peptide contains thirteen amino acid residues; six out of them may be D-amino acids. The gene cluster exhibited less than $40 \%$ sequence identity with its closest homologue from other bacterial species. This indicated that the compound encoded by this cluster may be a novel 


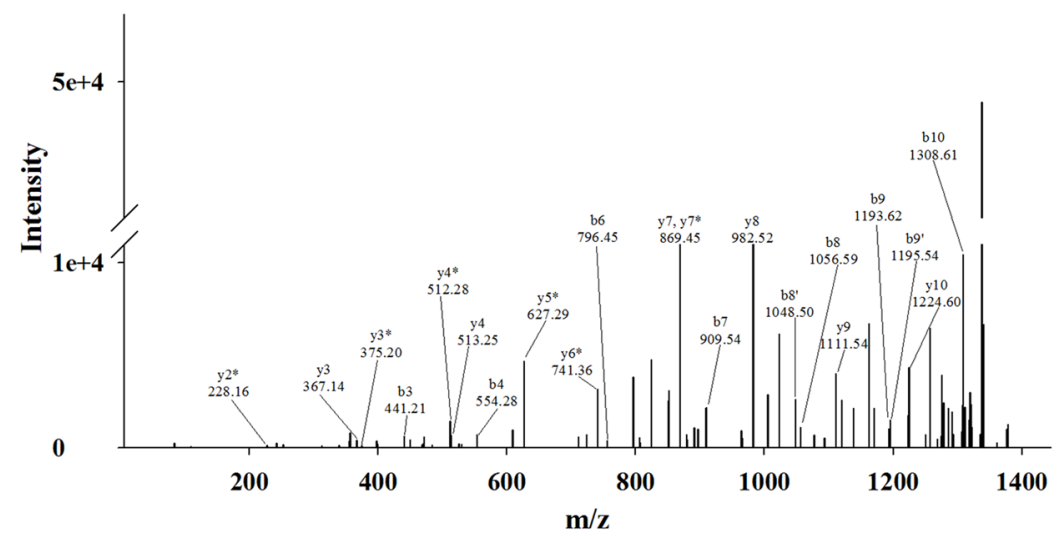

(A)

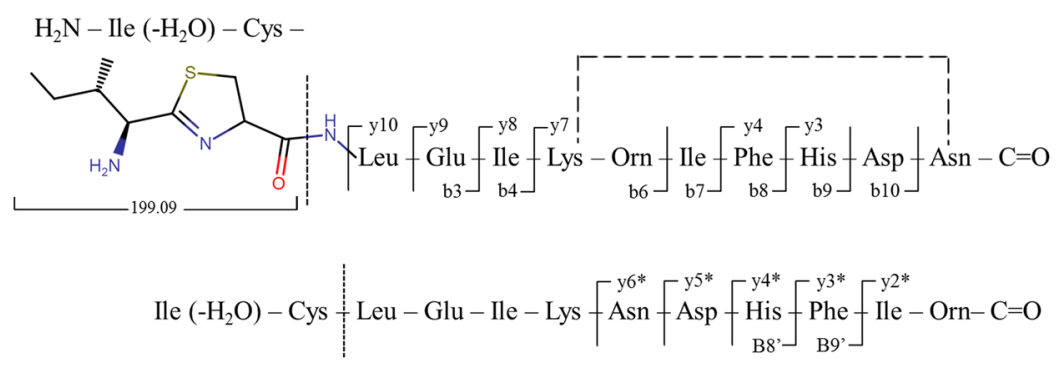

(B)

Figure 3. MSMS Spectrum of isolated compound. (A) Assignment of b and y ions; (B) Amino acid sequence deduced from the MSMS data. Both $\alpha$-carbonyl group and $\varepsilon$-amino group of the lysine residue at position 6 are involved in amide linkage with ornithine (position 7) and asparagine (position 12) respectively, to form a cyclic heptapeptide.
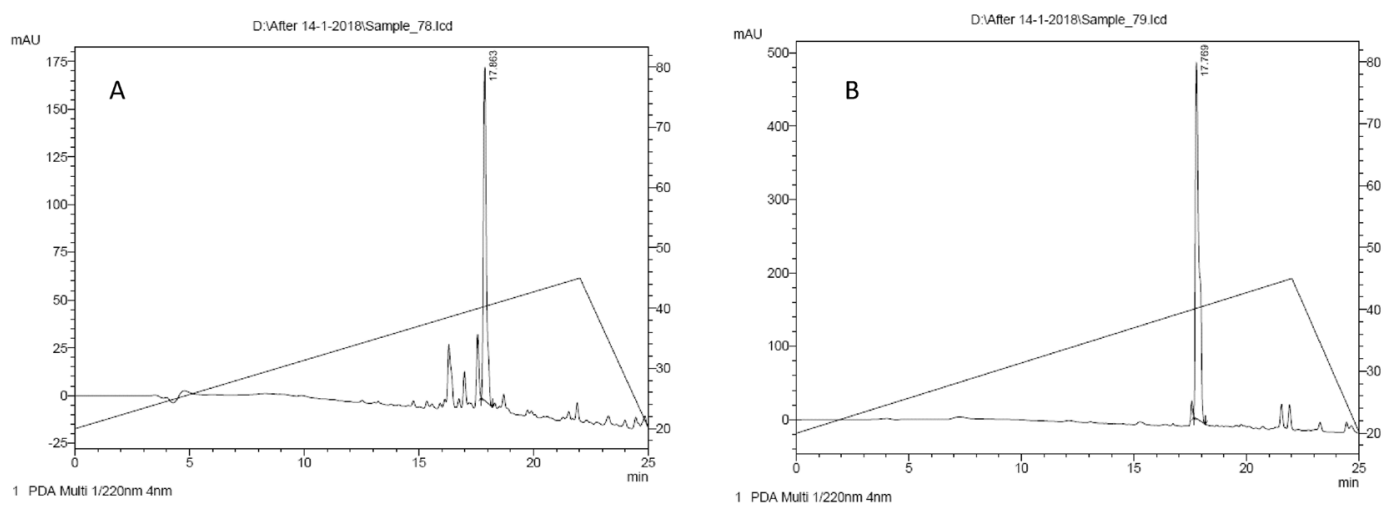

Figure 4. (A) HPLC profile of standard Bacitracin A; (B) HPLC profile of purified compound from SMB1 ${ }^{\mathrm{T}}$.

compound and needs further investigation. The other clusters also displayed low levels of homology with other peptide gene clusters. The comparison of bacteriocin and NRPS gene cluster with their homologs are given in the Supplementary Material (Supplementary Figs S4 and S5). The genome sequence of the strain SMB1 ${ }^{\mathrm{T}}$ has been deposited in the GenBank database and Accession Number QKRB00000000 was obtained.

Characterization of novel species $S M B 1^{\top}$. The strain $\mathrm{SMB1}^{\mathrm{T}}$ was characterized using polyphasic taxonomic approach. The 16S rRNA (Accession Number LT161878) gene was showing 98.6\% sequence similarity with Paenibacillus tarimensis. The sequence similarity with other members of the genus Paenibacillus is between $92.71 \%$ and $95.32 \%$. The phylogenetic tree analysis demonstrated that the strain $\mathrm{SMB} 1^{\mathrm{T}}$ belongs to the genus Paenibacillus and its closest homolog is Paenibacillus tarimensis (Fig. 6). The strain $\mathrm{SMB1}^{\mathrm{T}}$ is non-motile, straight rod-shaped Gram-positive bacterium with dimension $0.43-0.69 \mu \mathrm{m}$ wide $\times 2.25-4.18 \mu \mathrm{m}$ long (Fig. S6). 
A

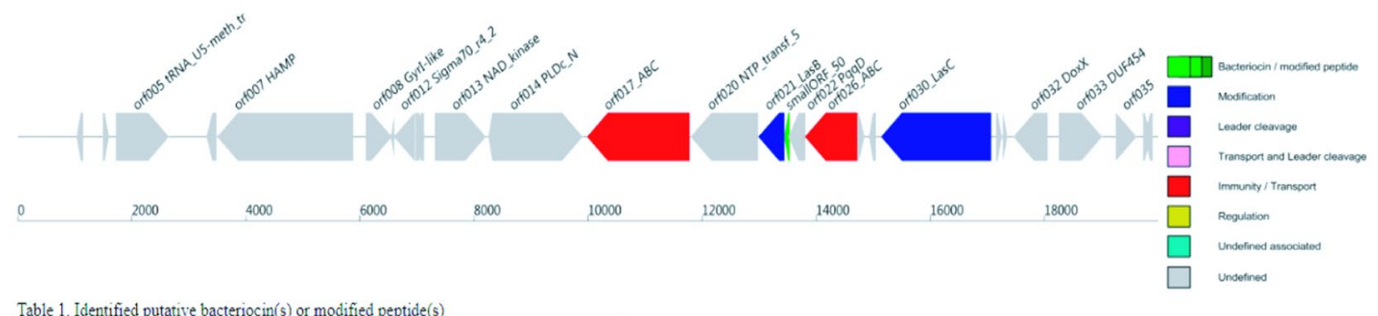

Table 1. Identified putative bacteriocin(s) or modified peptide(s)

Type Protein $1 \mathrm{D} \quad$ protein sequence

Lasso_peptide AOI_1;smallORF_50 MLPPQNVCNTASEEDLSCGAKYVSWPLLLSL

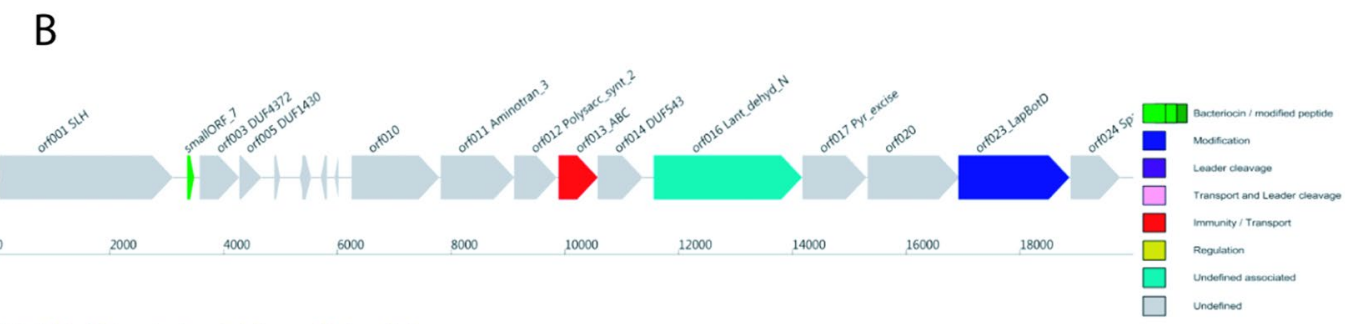

Table 1. Identified putative bacteriocin(s) or modified peptide(s)

Type Protein ID protein sequence

Thiopeptide AOI_1;smallORF_7 MLLALCWGSTSVALILPKSSKLSVIGLLEHKKILYNENGR

\section{C}

383 - Gene Cluster 42 . Type $=$ nrpa.
Show pHMM detection rules used

Legend:

$\square$ core biosynthetic genes $\square$ additional biosynthetic genes $\square$ transport-related genes $\square$ regulatory genes $\square$ other genes

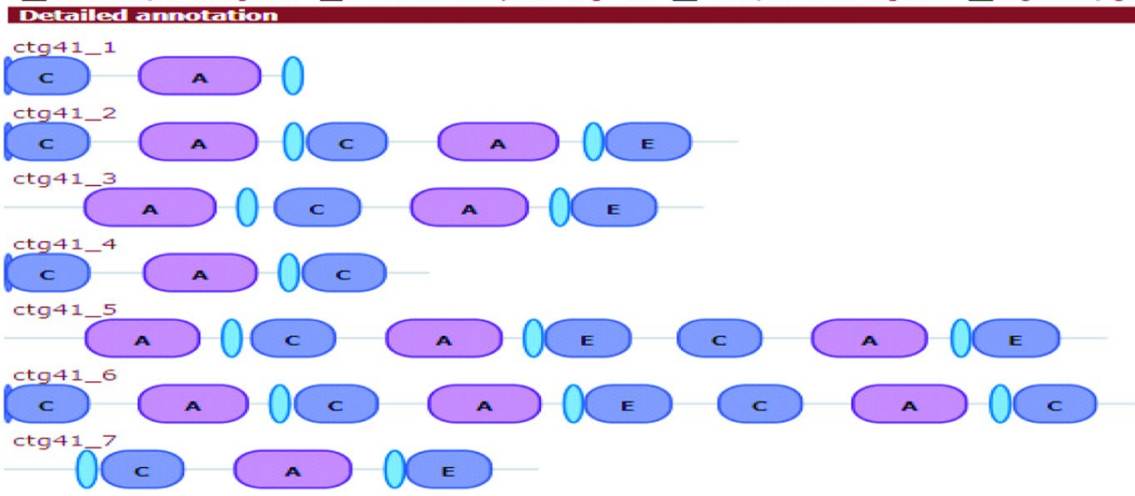

Figure 5. Antimicrobial biosynthetic gene cluster in the genome sequence of strain $\mathrm{SMB}^{\mathrm{T}}$ (A) Cluster 1, lassopeptide predicted using BAGEL3; (B) Cluster 2, thiopeptide, a putative bacteriocin predicted using BAGEL3; (C) Cluster 3, non-ribosomal peptide predicted using anti-SMASH.

The colonies were irregular with raised elevation, diameter 2-3 mm, cream color on ZMA plates, whereas after 48 hours in same conditions the colonies tend to appear reddish in color. The spore formation was noticed after $48 \mathrm{~h}$.

The strain $\mathrm{SMB} 1^{\mathrm{T}}$ was able to grow between $30^{\circ} \mathrm{C}$ to $42^{\circ} \mathrm{C}$ and had an optimum temperature for growth at $37^{\circ} \mathrm{C}$. The $\mathrm{pH}$ range for the growth was from $\mathrm{pH} 6.0$ to 9.0, with the optimum growth at $\mathrm{pH} 7.0$. Optimum growth occurred at salinities from $2 \%(\mathrm{NaCl}, \mathrm{w} / \mathrm{v})$ and the salinity range that the strain can withstand is $0-3 \%(\mathrm{NaCl}$, $\mathrm{w} / \mathrm{v})$. The phenotypic characteristics of the strain $\mathrm{SMB1}^{\mathrm{T}}$ in comparison to its closely related species are described in Table 2. The results observed using phenotypic fingerprinting (VITEK $2 \mathrm{GP}$ ) are represented in Table S1.The fatty acid profile (Table S2) revealed the presence of branched and saturated like C16:0 (18.17\%), C17:0 (4.06\%), iso-C15:0 (4.17\%), iso-C16:0 (5.83\%), iso-C17:0 (5.09\%), anteiso-C15:0 (48.86\%) and anteiso-C17:0 (13.82\%). Hydroxy fatty acids were absent. Overall fatty acid profile of strain $\mathrm{SMB1}^{\mathrm{T}}$ was same as those of the strain DSM$19409^{\mathrm{T}}$ and however, the saturated fatty acids C17:0 and branched fatty acids iso-C17: 0 was absent in DSM$19409^{\mathrm{T}}$. Fatty acids C14: 0, C16: $1 \omega 11 c$ and iso-C14: 0 was absent in strain SMB1 ${ }^{\mathrm{T}}$ but present in DSM-19409 ${ }^{\mathrm{T}}$. Hence, it clearly demonstrates the difference in their fatty acid profiles. The DNA base composition of strain $\mathrm{SMB}^{\mathrm{T}}$ was $54 \mathrm{~mol} \% \mathrm{G}+\mathrm{C}(\mathrm{Tm})$. According to the DNA-DNA hybridization, the relative binding ratio with 


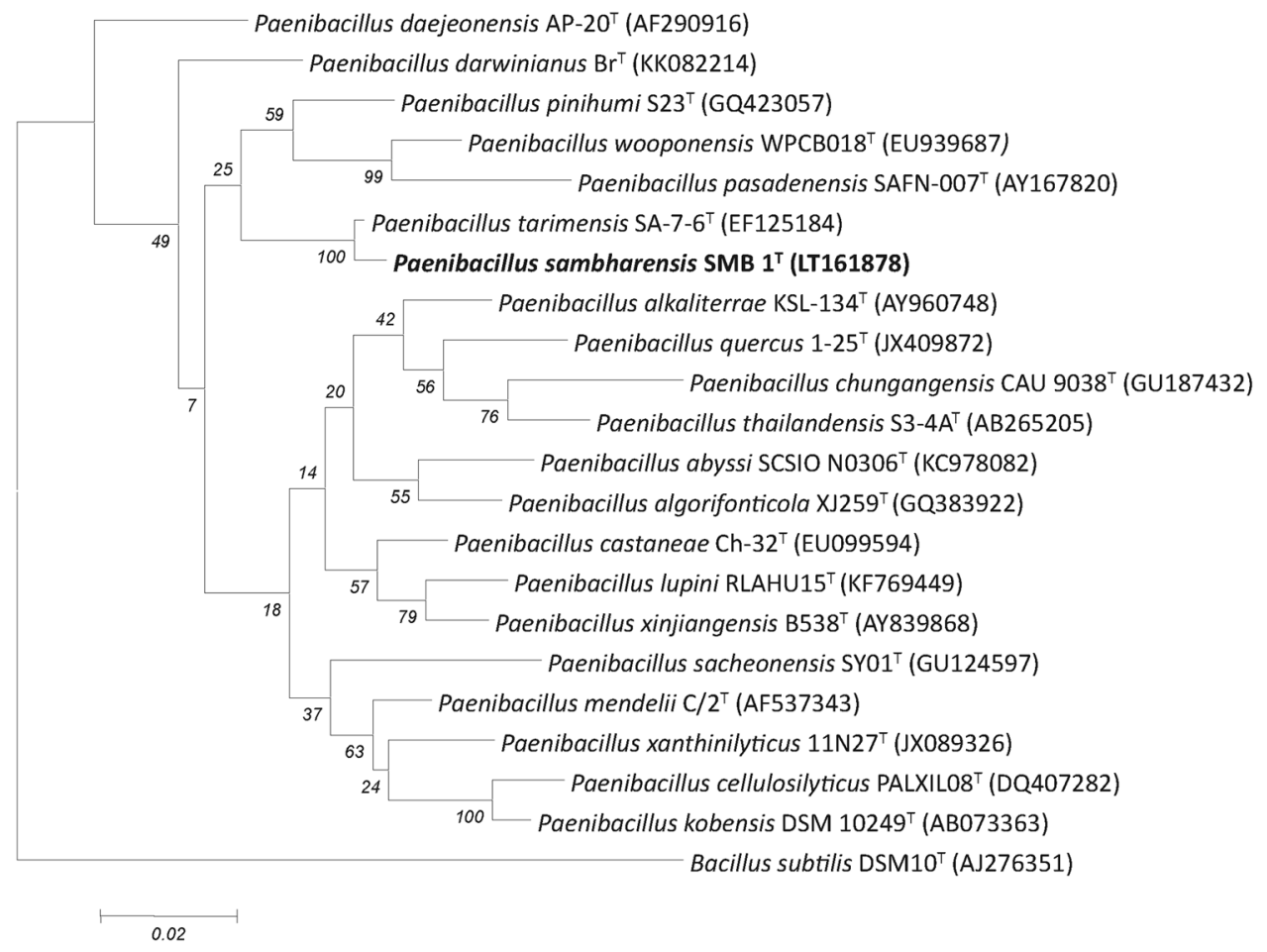

Figure 6. Neighbor-joining phylogenetic tree, based on 16S rRNA gene sequences, showing relationships between different strains of the genus Paenibacillus spp. Bacillus subtilis was taken as the outgroup. Bar, 0.02 substitutions per nucleotide position.

Paenibacillus tarimensis, DSM $19409^{\mathrm{T}}$ was $46.45 \%$ (results are obtained from the average of the triplicates). The relation was found to be significantly less in comparison to the threshold value for the species delineation i.e. $70 \%{ }^{21}$. These results demonstrate the distinction of the strain $\mathrm{SMB1}^{\mathrm{T}}$ from its closest neighbor. The digital protologue of this strain has been registered on their website (http://imedea.uib-csic.es/dprotologue/) under the taxonumber TA00612.

\section{Discussion}

Sambhar Lake is the one of the largest Salt Lake in India. It has the extreme hypersaline environment. These extreme conditions harbor microorganisms with valuable and distinct characteristics. The extremophiles survive the harsh and hyper environmental conditions and produce unique and uncommon bioactive molecules and secondary metabolites. These compounds are industrially stable and have many biotechnological applications ${ }^{22}$. The main objective of our study was to explore the diversity of the Sambhar Lake for the screening of the antimicrobial compounds. We isolated hundred bacterial strains from the lake samples and screened all of them for their antimicrobial activities using agar well diffusion assay. Fifteen isolates showed inhibitory activity against the indicator strains. The 16S rRNA gene sequencing data revealed that these isolates included four novel bacterial species, having pairwise similarity percentage less than or equal to $98.5 \%$. We recently published three out of four strains as novel species. In the present work, we studied the strain $S M B 1^{\mathrm{T}}$ for the purification and identification of the antimicrobial compound and also characterized it as a novel species. This strain had a pairwise sequence similarity of $98.67 \%$ with Paenibacillus tarimensis DSM $19409^{\mathrm{T}}$ while the sequence similarity with other members of this genus was between $92.71 \%$ and $95.32 \%$. So, we performed polyphasic taxonomic characterization to describe the strain. Different species of genus Paenibacillus were isolated and characterized till date from various ecological niches such as soils, plants, animals, polar Antarctic habitats, alkaline environments, marine sources or cold and desert environments ${ }^{23-26}$. The phylogenetic analysis based on the 16S rRNA gene sequences revealed that the strain $\mathrm{SMB} 1^{\mathrm{T}}$ is closely related to the Paenibacillus tarimensis DSM $19409^{\mathrm{T}}$ and they shared the same clade. The genus Paenibacillus is reported to have antesio-C15:0 as major cellular fatty acids ${ }^{20}$, likewise our results showed the major fatty of anteiso-C15:0 (48.86\%) in case of SMB1 ${ }^{\mathrm{T}}$ and anteiso-C15:0 (61.69\%) for Paenibacillus tarimensis DSM $19409^{\mathrm{T}}$. Major differences were also observed in the cellular fatty acids, as unsaturated fatty acids were absent in strain SMB1 ${ }^{\mathrm{T}}$, but they were present in the strain DSM 19409 ${ }^{\mathrm{T}}(\mathrm{C} 16: 1 \omega 11 \mathrm{c})$. Similarly, fatty acids C17:0 and iso-C17: 0 were present in our strain while absent in DSM 19409 . Moreover, the DNA-DNA hybridization results showed the relative binding percentage was below $70 \%$. Hence, it clearly supports that the strain $\mathrm{SMB}^{\mathrm{T}}$ is the novel species. Based upon the phenotypic and genotypic analyses, we concluded the strain SMB1 ${ }^{\mathrm{T}}$ belongs to the novel species of genus Paenibacilllus and thus we proposed the name Paenibacillus sambharensis sp. nov for this strain (sam.bhar.en'sis. N.L. masc. adj. sambharensis pertaining to Sambhar Lake). The type strain is $\mathrm{SMB1}^{\mathrm{T}}\left(=\mathrm{MTCC} 12884^{\mathrm{T}}=\mathrm{KCTC} 33895^{\mathrm{T}}\right)$. 


\begin{tabular}{|c|c|c|}
\hline Characteristics & $\begin{array}{l}\text { Paenibacillus } \\
\text { sambharensis } \\
\text { SMB } 1^{\mathrm{T}}\end{array}$ & $\begin{array}{l}\text { Paenibacillus } \\
\text { tarimensis } \\
\text { DSM-19409 }\end{array}$ \\
\hline Cell size & $\begin{array}{l}2.25- \\
4.18 \times 0.43-0.69\end{array}$ & $\begin{array}{l}3.0-6.0 \times 0.5- \\
0.8 \mu \mathrm{m}\end{array}$ \\
\hline Motility & - & + \\
\hline Flagella & - & + \\
\hline Endospore & + & + \\
\hline Colony color & Cream red & cream \\
\hline Salinity growth range (\%) & $0-3$ & $0-3$ \\
\hline Salinity Optimum (\%) & 2 & 2 \\
\hline $\begin{array}{l}\text { Temperature growth range } \\
\left({ }^{\circ} \mathrm{C}\right)\end{array}$ & $30-42$ & $25-45$ \\
\hline $\begin{array}{l}\text { Optimum growth temperature } \\
\left({ }^{\circ} \mathrm{C}\right)\end{array}$ & 37 & 37 \\
\hline pH growth range (Optimum) & $6-9(7)$ & $6-9(7.5)$ \\
\hline Oxygen requirement & + & + \\
\hline \multicolumn{3}{|l|}{ Biochemical: } \\
\hline Catalase & + & + \\
\hline Phenylalanine deamination & + & $\mathrm{w}$ \\
\hline Methyl red & - & + \\
\hline Voges Proskauer's & - & + \\
\hline Indole & - & - \\
\hline $\mathrm{H}_{2} \mathrm{~S}$ & - & - \\
\hline Oxidase & - & - \\
\hline \multicolumn{3}{|l|}{ Hydrolysis of: } \\
\hline Aesculin & + & + \\
\hline Gelatin & - & - \\
\hline ONPG & - & - \\
\hline Tween 80 & + & - \\
\hline Urea & - & - \\
\hline \multicolumn{3}{|l|}{ Utilization of: } \\
\hline Fructose & - & - \\
\hline Trehalose & + & + \\
\hline Xylose & + & + \\
\hline L-Arabinose & + & w \\
\hline Raffinose & - & - \\
\hline Melibiose & + & + \\
\hline Sucrose & - & - \\
\hline Mannitol & - & - \\
\hline Citrate & - & - \\
\hline Lactose & - & - \\
\hline Mannose & + & + \\
\hline Cellobiose & + & + \\
\hline Adonitol & - & - \\
\hline Rhamnose & + & - \\
\hline Melizitose & + & $\mathrm{w}$ \\
\hline $\mathrm{N}$-acetyl-D-glucosamine & - & - \\
\hline Xylitol & - & - \\
\hline D-Arabinose & - & $\mathrm{w}$ \\
\hline Malonate & - & - \\
\hline \multicolumn{3}{|c|}{ Antibiotic susceptibility ( $\mu \mathrm{g} / \mathrm{disc})$ : } \\
\hline Tetracycline (30) & $S$ & $\mathrm{~S}$ \\
\hline Neomycin (30) & S & S \\
\hline Cefazolin $(30)$ & I & S \\
\hline Penicillin G (2 units) & S & $\mathrm{R}$ \\
\hline \begin{tabular}{|l|} 
Gentamycin (10) \\
\end{tabular} & $S$ & $\mathrm{~S}$ \\
\hline Kanamycin (30) & $\mathrm{S}$ & $\mathrm{S}$ \\
\hline Polymixin B (300) & I & S \\
\hline
\end{tabular}




\begin{tabular}{|l|l|l|}
\hline Characteristics & $\begin{array}{l}\text { Paenibacillus } \\
\text { sambharensis } \\
\text { SMB 1 }^{\text {T }}\end{array}$ & $\begin{array}{l}\text { Paenibacillus } \\
\text { tarimensis } \\
\text { DSM-19409 }\end{array}$ \\
\hline Cefprozil (30) & I & S \\
\hline Amoxycillin (30) & S & I \\
\hline Cephanroxcil (30) & S & S \\
\hline Lincomycin (2) & S & R \\
\hline Cefalexin (30) & S & R \\
\hline Chloraphenicol (30) & S & S \\
\hline Vancomycin (30) & I & S \\
\hline Novobiocin (30) & I & I \\
\hline Chlortetracycline (30) & I & R \\
\hline DNA G + C content (mol\%) & 54.0 & 53.7 \\
\hline
\end{tabular}

Table 2. Features that distinguish strain Paenibacillus sambharensis $\mathrm{SMB}^{\mathrm{T}}$ from the closely related species of the genus Paenibacillus tarimensis DSM-19409 ${ }^{\mathrm{T}}$. +, Positive; -, negative; w, weakly positive; R, resistant; S, sensitive; I, moderately sensitive.

The Paenibacillus genus has been studied widely for producing a diversity of secondary metabolites, including enzymes, exopolysaccharides, and antimicrobial peptides and other industrially important bioactive molecules ${ }^{27}$. Polymyxins, which are active against Gram negatives and fusaricidins, the antifungal peptide are the best examples of antibiotic products of the Paenibacillus genus ${ }^{27}$. Paenibacillus also produces bacteriocins, for example, $P$. polymyxa NRRL B-30509 produces paenicidin ${ }^{28}$ and Paenibacillus sp. strain A3 produces penisin ${ }^{29}$. In the present research work, we have identified and characterized an antimicrobial peptide from our strain SMB1 ${ }^{\mathrm{T}}$. The whole genome analysis identified three novel biosynthetic gene clusters in this strain. We presumed that one of these clusters might be responsible for the observed antimicrobial activity. Hence we purified and characterized the antimicrobial compound from the fermentation broth. Using MS, MS/MS and amino analysis we confirmed that the compound is bacitracin A. Bioactivity was also found to be similar when assessed at the similar concentration, in comparison to standard bacitracin A. Though we were not able to obtain the complete biosynthetic cluster for the antimicrobial peptide bacitracin, but we found that the contig 383 of the genome sequence contains the genes encoding for the bacitracin synthesis. Recently, a draft genome sequence of a Paenibacillus polymyxa strain also revealed bacitracin biosynthetic gene cluster ${ }^{30}$. This further validates that the strain SMB1 ${ }^{\mathrm{T}}$ produces antimicrobial peptide bacitracin A. Bacitracin is a polypeptide known to be produced by Bacillus subtilis and Bacillus licheniformis $^{31}$. Apart from this, we also found novel biosynthetic clusters for the putative bacteriocin i.e. lassopeptide and thiopeptide. Thiopeptides and lasso peptides are known for their antimicrobial activities ${ }^{32}$. In a recent report, Paenibacillus dendritiformis $\mathrm{C} 454$ was reported to produce novel lasso peptide paeninodin ${ }^{33}$. Additionally, we also identified one biosynthetic gene cluster for the non-ribosomally synthezized peptide. This suggests that the strain $\mathrm{SMB} 1^{\mathrm{T}}$ holds the potential as antimicrobial producing species. To the best of our knowledge, this is the first report describing the production and purification of the antimicrobial compound bacitracin A from the genus Paenibacillus. Moreover, the other novel species isolated from salt lake also showed antimicrobial activity and are deposited in a public repository. These strains could be explored in future for the isolation of bioactive compounds. Additionally, the novel biosynthetic gene cluster found in the whole genome of strain SMB1 ${ }^{\mathrm{T}}$ could be heterologously expressed and checked for their antimicrobial activity. This approach has been used in several antimicrobial clusters, for example malacidins ${ }^{34}$. These BGCs are cryptic gene clusters and alternatively, they may be expressed when placed under strong inducible promoters. As explained in the report by, Zipperer A et al. 2016, the compound lugdunin was not initially produced by the strain Staphylococcus lugdunensis in the fermentation broth, so they expressed the biosynthetic gene cluster by adding the strong promoter to produce the strain in liquid broth ${ }^{8}$. This approach can also be done in case of these BGCs as they are showing similarity less than $40 \%$ to the already known BGCs. Overall, this research demonstrates that novel species harbored from extreme niche hold potential to produce antimicrobial compounds.

\section{Materials and Methods}

Isolation of bacterial strains and antimicrobial screening. Sediment and water samples were collected in the sterile $50 \mathrm{ml}$ polypropylene tubes (Tarsons, India) from different sites at Sambhar Lake, Rajasthan (GPS coordinates $26^{\circ} 55.520^{\prime} \mathrm{N} 075^{\circ} 11.827^{\prime} \mathrm{E}$ ). The $\mathrm{pH}$ at different sampling sites was $8-12$ and the temperature was $28^{\circ} \mathrm{C}-35^{\circ} \mathrm{C}$. Serially diluted samples were plated on different media such as Zobell marine agar (ZMA), Reasoner's $2 \mathrm{~A}$ Agar (R2A agar) with $2 \% \mathrm{NaCl}(\mathrm{w} / \mathrm{v})$, modified Zobell marine agar containing $\mathrm{NaCl}(2-10 \% \mathrm{w} / \mathrm{v})$ and $\mathrm{pH}$ range from 7-10 for the isolation of various halophilic bacteria. Optimization for salinity, $\mathrm{pH}$, and temperature was done to check the optimum growth parameters. The $\mathrm{pH}$ was adjusted to 8.0-10 with the $\mathrm{Na}_{2} \mathrm{CO}_{3}$ solution $(20 \%, \mathrm{w} / \mathrm{v})$ and incubated at $30^{\circ} \mathrm{C}$ and $37^{\circ} \mathrm{C}$ for $3-7$ days. The plates were monitored regularly and each unique colony was purified and preserved in $20 \%$ glycerol stock at $-80^{\circ} \mathrm{C}$. The isolates were screened for their antimicrobial activity using agar well diffusion assay against Staphylococcus aureus ATCC 25923, Bacillus subtilis ATCC 6633 (Equivalent MTCC 441), E. coli MTCC 1610 and Candida albicans MTCC 224. Two to three colonies were inoculated in Zobell marine broth and incubated at $37^{\circ} \mathrm{C}$ for $24-48 \mathrm{~h}$. The cultures were harvested by centrifugation after $48 \mathrm{~h}$, and the crude fermentation extracts using Diaion HP20 resins were prepared as described in the next section. The cell-free supernatants $(100 \mu \mathrm{l})$ at $24 \mathrm{~h}$ and $48 \mathrm{~h}$ along with the crude extracts were loaded on seeded agar plates containing the indicator strain. The plates were incubated for $12-24 \mathrm{~h}$ and 
zones of inhibition were observed. The sterile medium without inoculation of culture was extracted in the similar way and served as negative control. Positive isolates having inhibitory activity were identified using $16 \mathrm{~S}$ rRNA gene sequencing. Genomic DNA was extracted using DNA isolation kit (Zymo Research, California, D6005) and 16S rRNA gene was amplified. The sequencing was performed with the Genetic Analyzer ABI 3130XL (Applied Biosystems, California, USA). The sequence obtained was analyzed using EzTaxon sequence based database (https://www.ezbiocloud.net).

Purification of the antimicrobial compound from the strain SMB1 ${ }^{\top}$. Paenibacillus sp. SMB1 ${ }^{\mathrm{T}}$ was grown in $700 \mathrm{ml} \mathrm{ZMB}$ in $2 \mathrm{~L}$ flask at $37^{\circ} \mathrm{C}$ and $180 \mathrm{rpm}$. After $36 \mathrm{~h}$, the culture was harvested by centrifugation at $12,000 \times \mathrm{g}$ for $15 \mathrm{~min}$. Subsequently, the cell-free supernatant was incubated with Diaion HP-20 (Supelco, Sigma-Aldrich, USA) resins $(2 \% \mathrm{w} / \mathrm{v})$ for $3 \mathrm{~h}$. The resins were washed with $10 \%$ methanol and the bound components were eluted with $100 \%$ methanol. The solvent was evaporated under vacuum (Rotary evaporator BUCHI R-300). The crude extract was re-dissolved in Milli-Q. The antimicrobial compound was partially purified by cation-exchange chromatography (SP Sepharose, $10 \mathrm{mM}$ ammonium acetate, $\mathrm{pH}$ 5.0). Bioactivity-guided fractionation was performed and the active fractions were pooled. The cation-active fraction was dialyzed using the $0.5-1 \mathrm{kDa}$ membrane. Final purification of the antimicrobial compounds was carried out by high-performance liquid chromatography (HPLC) (SHIMADZU with PDA detector, XBridge Waters column, C18, $5 \mu \mathrm{m}$, $10 \times 250 \mathrm{~mm}$ ). The mobile phase consisted of solvent A, $5 \mathrm{mM}$ ammonium acetate buffer $(\mathrm{pH} 5.5)$ and solvent B, $100 \%$ acetonitrile. The gradient elution was performed as $5-45 \%$ solvent B in $40 \mathrm{~min}, 45-90 \%$ B in 12 min and reverse $90-5 \%$ B in $8 \mathrm{~min}$. The flow rate was kept at $3.0 \mathrm{ml} / \mathrm{min} .500 \mu \mathrm{l} \mathrm{sample}$ was injected and the peaks were analyzed at $220 \mathrm{~nm}$. All peaks were collected and assayed for bioactivity. The active peak was identified and purity was determined by analytical HPLC. Antimicrobial activity of the purified compound was checked against Staphylococcus aureus ATCC 25923.

Mass spectrometry and amino acid analysis. The purified compound was subjected to LC-ESI-MS (Agilent 6550 I funnel QTOF) in positive ion mode. The mass spectrum was analyzed in the range of 400$4000 \mathrm{~m} / \mathrm{z}$. For MALDI-TOF analysis, the sample was mixed with $\alpha$-cyano-4-hydroxycinnamic acid (CHCA) matrix and mass spectrum was obtained on MALDI-TOF mass spectrometer (AB Sciex 5800). MS/MS analysis was performed on the same instrument with TOF-TOF analyzer. The amino acid analysis was carried out with PICO-TAG amino analysis system (Waters) as per the manufacturer's instructions.

Comparative analysis of antimicrobial compound with standard bacitracin A. Bacitracin A was purchased from Alfa Aeser, Thermofisher Scientific, India. MS and MS/MS analysis of bacitracin A were performed in a similar way as described for antimicrobial compound isolated in this study. The MS/MS spectrum of isolated compound was compared with bacitracin A data and manually annotated in details. Also, the retention time of both compounds was compared in analytical HPLC under the similar conditions. Bacitracin A and isolated compound were dissolved at the same concentration $(0.5 \mathrm{mg} / \mathrm{ml})$ and their antimicrobial activity was checked against Micrococcus luteus and Staphylococcus aureus.

Whole genome sequencing and bioinformatics analysis. Genomic DNA was isolated from the strain $\mathrm{SMB1}^{\mathrm{T}}$ and the whole genome sequencing was performed on Illumina HiSeq sequencing platform using paired end library. Around 4-5 Mb data was obtained. De Novo assembly was performed using Spades, MaSuRCa, ABySS, and Velvet. We used ABySS assembly for all further downstream analysis since it had better statistics than all other assemblies generated ${ }^{35} .63$ contigs were obtained with the ABySS assembly. The functional analysis was performed using Rapid Annotation using Subsystems Technology (RAST) version 2.0 $0^{36}$. BAGEL $3^{37}$ and anti-SMASH ${ }^{38}$ were used to predict the biosynthetic gene clusters for secondary metabolites and antimicrobial peptides. Default search parameters were used in antiSMASH and BAGEL3 mining.

Characterization of $\mathrm{SMB} 1^{\top}$ strain. Sequence similarity search of $\mathrm{SMB1}^{\mathrm{T}}$ strain indicated that Paenibacillus tarimensis and Paenibacillus lacus were the closest phylogenetic neighbors, with a pair-wise sequence similarity of $98.6 \%, 95.5 \%$ respectively. Thus, the strain $\mathrm{SMB}^{\mathrm{T}}$ was characterized in comparison to its closest type strain Paenibacillus tarimensis DSM $19409^{\mathrm{T}}$. The phylogenetic tree was constructed using the neighbor-joining method in the MEGA6 software.

Morphological characterization. The strains SMB1 ${ }^{\mathrm{T}}$ and DSM $19409^{\mathrm{T}}$ were grown in Zobell Marine Agar medium at $37^{\circ} \mathrm{C}$ for $48 \mathrm{~h}$. The shape, size, color, margin, and elevation of the colonies were observed. The cell shape was observed using phase contrast microscopy at 1000X magnification (BX51; Olympus, Japan). The cell size was measured using the transmission electron microscopy. The cells were grown in the Zobell Marine broth and the bacterial pellet was washed with PBS ( $\mathrm{pH} 7.4) .10 \mu \mathrm{l}$ of the sample was loaded on the copper carbon-coated grids and kept undisturbed for 10 minutes (300mesh), (Polysciences, Inc. USA cat \#24933-25). After drying, 2\% PTA (phosphotungstic acid) at $\mathrm{pH} 6$ was added for 3 minutes and the grid was dried and observed under TEM (JEOL JEM-2100; Camera, ES500W Model 782).

Physiological characterization. KB003:Hi25 ${ }^{\mathrm{TM}}$ Carbohydrate Identification Kit and KB009 (HiMedia Laboratories, India) were used for other biochemical tests. Strains SMB1 ${ }^{\mathrm{T}}$ and DSM $19409^{\mathrm{T}}$ were grown in Zobell Marine Agar medium until the log phase; the turbidity was adjusted to $0.1 \mathrm{OD}$ at $620 \mathrm{~nm}$. The specified wells in the kit were inoculated with $50 \mu \mathrm{l}$ of the samples and the strips were incubated at $37^{\circ} \mathrm{C}$ for $18-24$ hours. The reagents were added in the selective wells as per the manufacturer's instructions ${ }^{39}$. The change in color was observed and results were recorded. 
Effect of temperature, $\mathrm{pH}$ and $\mathrm{NaCl}$ concentrations on the growth. Growth at varying temperature conditions (10, $15,25,30,37,38,42,50$ and $55^{\circ} \mathrm{C}$ ) was measured with the Zobell marine agar plates streaked with the strains. To check the effect of $\mathrm{pH}$ the strains were inoculated in ZMA at pH 5.0, 5.7, 6.8, 8.0, 9.0 and 11.0 adjusted with different buffer systems such as; $0.1 \mathrm{M}$ citric acid/ $0.1 \mathrm{M}$ sodium citrate $\mathrm{pH}$ 4.0-5.0, $0.1 \mathrm{M} \mathrm{KH}_{2} \mathrm{PO}_{4} / 0.1 \mathrm{M} \mathrm{NaOH}$ $\mathrm{pH}$ 6.0-8.0, $0.1 \mathrm{M} \mathrm{NaHCO}_{3} / 0.1 \mathrm{M} \mathrm{Na}_{2} \mathrm{CO}_{3}$ (pH 9.0-10.0). Growth at various $\mathrm{NaCl}$ concentrations $(0,0.5,1,2,4$, $6,8,9,10,12$ and $14 \%(\mathrm{w} / \mathrm{v}))$ was monitored as described previously ${ }^{40}$.

Phenotypic fingerprinting using VITEK -2. VITEK ${ }^{\circledR} 2$ system was used for the phenotypic fingerprinting of the cultures SMB1 ${ }^{\mathrm{T}}$ and DSM $19409^{\mathrm{T}}$. The cultures were analyzed based on their metabolic activities for the utilization of various nitrogen, carbon, and other nutrient sources. VITEK 2 is the automated system, it contains 64 welled VITEK ${ }^{\circledR} 2$ GN cards (France) having different substrates in each well. The bacterial cell culture (diluted in $0.45 \%(\mathrm{w} / \mathrm{v})$ of $\mathrm{NaCl}$ ) with the OD 0.5 measured by DensiCheck meter (bioMe'rieux) was used in an automated sampling system the cards were incubated in the in-build incubator in VITEK 2 machine. The results were recorded.

Antibiotics susceptibility assay. The susceptibility of strain $\mathrm{SMB1}{ }^{\mathrm{T}}$ and the DSM $19409^{\mathrm{T}}$ to different antibiotics was checked using disc diffusion assay as per Clinical and Laboratory Standards Institute guidelines ${ }^{41}$. The antibiotics discs (Hi-Media, India) used were Tetracycline (30 mcg), Neomycin (30), Penicillin G (2 units), Gentamycin $(10 \mathrm{mcg})$, Kanamycin $(30 \mathrm{mcg})$, Amoxycillin $(30 \mathrm{mcg})$, Cephanroxcil $(30 \mathrm{mcg})$, Lincomycin $(2 \mathrm{mcg})$, Cefalexin (30 mcg), Chloramphenicol (30 mcg), Cefazolin (30 mcg), Polymixin B (300 units), Cefprozil (30), Vancomycin $(30 \mathrm{mcg})$, Novobiocin $(30 \mathrm{mcg})$ and Chlortetracycline $(30 \mathrm{mcg})$.

Fatty acid methyl ester (FAMEs) analysis. The strains SMB1 ${ }^{\mathrm{T}}$ and DSM $19409^{\mathrm{T}}$ were grown till the logarithmic phase. Cellular fatty acid methyl esters (FAMEs) were obtained according to manufacturer's protocol. The samples containing the FAMEs were subjected to GC (6890) and the different fatty acids were separated and analyzed with the Sherlock Microbial Identification System (MIDI-6890 with database TSBA6) ${ }^{42}$.

DNA-DNA Hybridisation. The G $+\mathrm{C}$ content of genomic DNA of the strain SMB- $1^{\mathrm{T}}$ and the type strain was determined spectrophotometrically (lambda 35, Perkin Elmer, Waltham, MA, USA) by using thermal denaturation method ${ }^{43}$. For DNA-DNA Hybridisation genomic DNA was isolated for both the strains. The fluorimetry method was used to measure the relative binding ratio of the samples. Step One Plus Real-Time PCR system (Applied Biosystems) was used with the thermal cycler in 96-well plate as explained by ${ }^{44}$. 2X SSC buffer was used for dissolving the DNA. SYBR Green in the ratio 1:10000 was used for the detection of the binding. The program used for the experiment was denaturation at $95^{\circ} \mathrm{C}$ for $10 \mathrm{~min}$, the re-association temperature was $74.4^{\circ} \mathrm{C}$ for $10 \mathrm{sec}(240$ cycles $)$ and holding stage $25^{\circ} \mathrm{C}$ for $5 \mathrm{~min}$. The florescence readings were recorded and the relative binding percentage was calculated according to the method reported by ${ }^{45,46}$.

Accession numbers. 16S rRNA gene sequence was submitted to GenBank/EMBL/DDBJ under Accession Number LT161878. The genome sequence of the strain SMB1 ${ }^{\mathrm{T}}$ has been deposited in the GenBank/NCBI database and Accession Number QKRB00000000 was obtained.

Ethical approval. This article does not contain any studies with human participants or animals performed by any of the authors.

This manuscript is IMTECH communication number 039/2018.

\section{References}

1. Nordmann, P., Dortet, L. \& Poirel, L. Carbapenem resistance in Enterobacteriaceae: here is the storm! Trends in molecular medicine 18, 263-272 (2012).

2. WHO. Worldwide country situation analysis: response to antimicrobial resistance. (2015).

3. Payne, D. J., Gwynn, M. N., Holmes, D. J. \& Pompliano, D. L. Drugs for bad bugs: confronting the challenges of antibacterial discovery. Nature reviews Drug discovery 6, 29 (2007).

4. Chellat, M. F. \& Riedl, R. Pseudouridimycin: The First Nucleoside Analogue That Selectively Inhibits Bacterial RNA Polymerase. Angewandte Chemie International Edition 56, 13184-13186 (2017).

5. Fisch, K. M. \& Schaeberle, T. F. Toolbox for Antibiotics Discovery from Microorganisms. Archiv der Pharmazie 349, 683-691 (2016).

6. Ling, L. L. et al. A new antibiotic kills pathogens without detectable resistance. Nature 517, 455 (2015).

7. Pantel, L. et al. Odilorhabdins, antibacterial agents that cause miscoding by binding at a new ribosomal site. Molecular cell 70, 83-94. e87 (2018).

8. Zipperer, A. et al. Human commensals producing a novel antibiotic impair pathogen colonization. Nature 535, 511 (2016).

9. Kamat, T. \& Kerkar, S. Bacteria from Salt Pans: a potential resource of antibacterial metabolites. Recent Research in Science and Technology 3 (2011).

10. Hashemi, T., Baseri, S. M. \& Bahador, N. Isolation of Halophilic Bacteria from Maharlu salt Lake-Iran and their evaluation for the production of bioactive compounds (2014).

11. Sawale, A., Kadam, T., Karale, M. \& Kadam, O. Antimicrobial activity of secondary metabolites from halophilic Bacillus pumilus sp. Int. J. Curr. Microbiol. App. Sci 3, 506-512 (2014).

12. Azemin, A., Klappa, P. \& Omar, M. S. S. Bacteriocin isolated from Halomonas sp.: a bacterial DING protein. The Malaysian Journal of Analytical Sciences 4, 831-840 (2015).

13. Essghaier, B. et al. Antimicrobial behavior of intracellular proteins from two moderately halophilic bacteria: strain J31 of Terribacillus halophilus and strain M3-23 of Virgibacillus marismortui. Journal of Plant Pathology \& Microbiology 5, 1 (2014).

14. Singh, H. et al. Salibacterium nitratireducens sp. nov., a haloalkalitolerant bacterium isolated from a water sample from Sambhar salt lake, India. International journal of systematic and evolutionary microbiology (2018).

15. Singh, H. et al. Bacillus alkalilacus sp. nov., isolated from a sediment sample from a lake in India. International journal of systematic and evolutionary microbiology (2018).

16. Singh, H. et al. Bacillus lacus sp. nov., isolated from a water sample of a salt lake in India. International journal of systematic and evolutionary microbiology (2018). 
17. Lockhart, I. \& Abraham, E. The amino acid sequence in bacitracin A. Biochemical Journal 58, 633 (1954).

18. Stone, K. J. \& Strominger, J. L. Mechanism of action of bacitracin: complexation with metal ion and C55-isoprenyl pyrophosphate. Proceedings of the National Academy of Sciences 68, 3223-3227 (1971).

19. Delcher, A. L., Bratke, K. A., Powers, E. C. \& Salzberg, S. L. Identifying bacterial genes and endosymbiont DNA with Glimmer. Bioinformatics 23, 673-679 (2007).

20. Ash, C., Priest, F. G. \& Collins, M. D. Molecular identification of rRNA group 3 bacilli (Ash, Farrow, Wallbanks and Collins) using a PCR probe test. Antonie van Leeuwenhoek 64, 253-260 (1993).

21. Wayne, L. et al. Report of the ad hoc committee on reconciliation of approaches to bacterial systematics. International Journal of Systematic and Evolutionary Microbiology 37, 463-464 (1987).

22. Hamedi, J., Mohammadipanah, F. \& Ventosa, A. Systematic and biotechnological aspects of halophilic and halotolerant actinomycetes. Extremophiles 17, 1-13 (2013).

23. Daane, L. et al. PAH-degradation by Paenibacillus spp. and description of Paenibacillus naphthalenovorans sp. nov., a naphthalenedegrading bacterium from the rhizosphere of salt marsh plants. International journal of systematic and evolutionary microbiology $\mathbf{5 2}$, 131-139 (2002)

24. Kishore, K. H., Begum, Z., Pathan, A. A. K. \& Shivaji, S. Paenibacillus glacialis sp. nov., isolated from the Kafni glacier of the Himalayas, India. International journal of systematic and evolutionary microbiology 60, 1909-1913 (2010).

25. Montes, M. J., Mercadé, E., Bozal, N. \& Guinea, J. Paenibacillus antarcticus sp. nov., a novel psychrotolerant organism from the Antarctic environment. International journal of systematic and evolutionary microbiology 54, 1521-1526 (2004).

26. Scheldeman, P. et al. Paenibacillus lactis sp. nov., isolated from raw and heat-treated milk. International Journal of Systematic and Evolutionary Microbiology 54, 885-891 (2004).

27. Grady, E. N., MacDonald, J., Liu, L., Richman, A. \& Yuan, Z.-C. Current knowledge and perspectives of Paenibacillus: a review. Microbial cell factories 15, 203 (2016).

28. Lohans, C. T. et al. Structural characterization of the highly cyclized lantibiotic paenicidin A via a partial desulfurization/reduction strategy. Journal of the American Chemical Society 134, 19540-19543 (2012).

29. Baindara, P. et al. Characterization of the antimicrobial peptide penisin, a class Ia novel lantibiotic from Paenibacillus sp. strain A3. Antimicrobial agents and chemotherapy 60, 580-591 (2016).

30. Li, Y., Li, Q., Li, Y., Gao, J. \& Fan, X. Draft genome sequence of Paenibacillus polymyxa KF-1, an excellent producer of microbicides. Genome announcements 4, e00727-00716 (2016).

31. Azevedo, E., Rios, E., Fukushima, K. \& Campos-Takaki, G. Bacitracin production by a new strain ofBacillus subtilis. Applied biochemistry and biotechnology 42, 1 (1993).

32. Zhao, N., Pan, Y., Cheng, Z. \& Liu, H. Lasso peptide, a highly stable structure and designable multifunctional backbone. Amino acids 48, 1347-1356 (2016).

33. Zhu, S. et al. Insights into the unique phosphorylation of the lasso peptide paeninodin. Journal of Biological Chemistry 291, 13662-13678 (2016).

34. Hover, B. M. et al. Culture-independent discovery of the malacidins as calcium-dependent antibiotics with activity against multidrug-resistant Gram-positive pathogens. Nature microbiology 3, 415 (2018).

35. Gurevich, A., Saveliev, V., Vyahhi, N. \& Tesler, G. QUAST: quality assessment tool for genome assemblies. Bioinformatics 29, 1072-1075 (2013).

36. Aziz, R. K. et al. The RAST Server: rapid annotations using subsystems technology. BMC genomics 9, 75 (2008).

37. van Heel, A. J., de Jong, A., Montalban-Lopez, M., Kok, J. \& Kuipers, O. P. BAGEL3: automated identification of genes encoding bacteriocins and (non-) bactericidal posttranslationally modified peptides. Nucleic acids research 41, W448-W453 (2013).

38. Weber, T. et al. antiSMASH 3.0-a comprehensive resource for the genome mining of biosynthetic gene clusters. Nucleic acids research 43, W237-W243 (2015).

39. Kiran, S., Swarnkar, M. K., Mayilraj, S., Tewari, R. \& Gulati, A. Paenibacillus ihbetae sp. nov., a cold-adapted antimicrobial producing bacterium isolated from high altitude Suraj Tal Lake in the Indian trans-Himalayas. Systematic and applied microbiology 40, 430-439 (2017).

40. Kumar, A. et al. Shivajiella indica gen. nov., sp. nov., a marine bacterium of the family "Cyclobacteriaceae" with nitrate reducing activity. Systematic and applied microbiology 35, 320-325 (2012).

41. Wayne, P. Performance standards for antimicrobial susceptibility testing: Twenty Fifth International Supplement M100-S25. Clinical and Laboratory Standards Institute (2015)

42. Sasser, M. Identification of bacteria by gas chromatography of cellular fatty acids. (1990).

43. Mandel, M. \& Marmur, J. In Methods in enzymology Vol. 12 195-206 (Elsevier, 1968).

44. Loveland-Curtze, J., Miteva, V. I. \& Brenchley, J. E. Evaluation of a new fluorimetric DNA-DNA hybridization method. Canadian journal of microbiology $57,250-255$ (2011).

45. Ley, J. D., Cattoir, H. \& Reynaerts, A. The quantitative measurement of DNA hybridization from renaturation rates. The FEBS Journal 12, 133-142 (1970).

46. Gillis, M., Ley, J. D. \& Cleene, M. D. The determination of molecular weight of bacterial genome DNA from renaturation rates. The FEBS Journal 12, 143-153 (1970).

\section{Acknowledgements}

We are highly thankful to the Director CSIR-IMTECH for all the facilities provided to conduct this work. The research fellowship of H.S. is provided by Indian Council of Medical Research (ICMR), Government of India is highly acknowledged. We thank Professor Aharon Oren for his expert suggestion concerning the correct species epithet and Latin etymology. We also thank Mr. Deepak Bhatt for technical assistance in 16S rRNA gene sequencing and Dr. Venkata Ramana for his help in the data analysis for DDH experiment. Dr. P Anil Kumar is thankful to the Department of Science and Technology (DST) -Science and Engineering Research Board (SERB) for funding (project SB/YS/LS-09/2014).

\section{Author Contributions}

H.S. and M.K. did the sampling and isolation of the bacteria. H.S., M.K. and M.J. performed the experiments, data analysis, and manuscript write-up. A.K., H.N. and S.M. planned, supervised and analyzed the study. H.S. and M.K. contributed equally to this work.

Additional Information

Supplementary information accompanies this paper at https://doi.org/10.1038/s41598-019-47879-x.

Competing Interests: The authors declare no competing interests. 
Publisher's note: Springer Nature remains neutral with regard to jurisdictional claims in published maps and institutional affiliations.

(c) (i) Open Access This article is licensed under a Creative Commons Attribution 4.0 International License, which permits use, sharing, adaptation, distribution and reproduction in any medium or format, as long as you give appropriate credit to the original author(s) and the source, provide a link to the Creative Commons license, and indicate if changes were made. The images or other third party material in this article are included in the article's Creative Commons license, unless indicated otherwise in a credit line to the material. If material is not included in the article's Creative Commons license and your intended use is not permitted by statutory regulation or exceeds the permitted use, you will need to obtain permission directly from the copyright holder. To view a copy of this license, visit http://creativecommons.org/licenses/by/4.0/.

(c) The Author(s) 2019 